\title{
CORRIGENDUM
}

\section{A cascade from disregard for rules of conduct at preschool age to parental power assertion at early school age to antisocial behavior in early preadolescence: Interplay with the child's skin conductance level-CORRIGENDUM}

\author{
GRAZYNA KOCHANSKA, ${ }^{a}$ REBECCA L. BROCK, ${ }^{b}$ AND LEA J. BOLDT ${ }^{a}$ \\ ${ }^{a}$ University of Iowa; and ${ }^{b}$ University of Nebraska-Lincoln \\ doi:10.1017/S0954579416000547, published by Cambridge University Press, 15 July 2016
}

There were typographical errors in three values in our original article. On page 5, right-hand column, in the fourth set of alpha values in the middle of the third full paragraph, the correct values are the following:

... At age 12, we also included antisocial personality disorder (five items, $\alpha \mathrm{s}=0.87$ and 0.76 , respectively). At each age, ..."

On page 6, left-hand column, in the first full paragraph, the correct range of scores is the following:

\section{Reference}

Kochanska, G., Brock, R. L., \& Boldt, L. J. (2016). A cascade from disregard for rules of conduct at preschool age to parental power assertion at early school age to antisocial behavior in early preadolescence: Interplay with
To create the final antisocial score, we standardized and averaged the eight scores (four for each parent: age $10 \mathrm{CSI}-4$ and ICU, and age 12 ASI-4R and ICU; $M=0.03, S D=0.79$, range $=-1.14$ to 3.62$) \ldots$."

We regret these errors and any problems they may have caused.

the child's skin conductance level. Development and Psychopathology. Advance online publication. doi:10.1017/S0954579416000547 